\title{
USING A MANUFACTURING EXECUTION SYSTEM (MES) IN A PROJECT BASED LEARNING CONTEXT IN THE MASTER DEGREE IN ORGANISATIONAL AND LOGISTICS ENGINEERING
}

\author{
Manuel Díaz-Madroñero ${ }^{1,2}$, Raúl Poler ${ }^{1,2}$, Francisco Fraile ${ }^{2}$, Raquel Sanchis ${ }^{1,2}$ \\ ${ }^{1}$ Dpto. Organización de Empresas, Escuela Politécnica Superior de Alcoy, Universitat \\ Politècnica de València (SPAIN) \\ ${ }^{2}$ Research Centre on Production Management and Engineering (CIGIP), Universitat \\ Politècnica de València (SPAIN)
}

\begin{abstract}
In this article the use of a Manufacturing Execution System (MES) in the Information Systems and Supply and Demand Management subjects is illustrated based on the project-based learning methodology. These subjects belong to the University Master's Degree in Organisational and Logistics Engineering (MOLE) given at the Campus of Alcoy of the Universitat Politècnica de València. The objective of this Master is to train professionals who will be able to analyze, model, design, implement and improve complex systems in order to offer products and services with the highest possible productivity, quality, reliability and efficiency. In this sense, one of the specific skills to be acquired by its graduates is the ability to select and implement the most appropriate information systems and information and communication technologies to support the information flows through the various departments of the company such as purchasing, logistics, production, processes, costs, human resources, etc. Therefore, firstly, the MOLE Degree is globally presented, contextualizing the subjects previously mentioned by focusing on skills, and on coordinating and organizing the subject and teaching-learning methodologies whose thematic units are also detailed. According Bridgefield Group [1] a MES is a production scheduling and control system for analyzing and reporting resources availabilities, planning production orders and collecting detailed manufacturing data. In this sense, the main characteristics of MES are overviewed focusing on the benefits they can offer to industrial companies. Subsequently, the MESView software [2], the MES software selected to be used in practical classes of the related subjects, is analyzed focusing on its most outstanding features. A case study inspired by an industrial company that currently uses MESView for tracking its manufacturing activities is presented and considered for developing the practical classes of Information Systems and Supply and Demand Management subjects with this software. The main contribution of this communication is to illustrate the use of a commercial MES in the MOLE, so that it can serve as a reference point for the elaboration of teaching materials in the field of subjects related to information systems and production management.
\end{abstract}

Keywords: MES, information systems, supply management, demand management.

\section{INTRODUCTION}

In the current dynamic industrial context, technology is crucial to face the challenges of the enterprises. For this reason, companies need professionals with the ability to select and implement the most appropriate information systems and information and communication technologies to support the information flows through the various departments of the company such as purchasing, logistics, production, processes, costs, human resources, etc.

Therefore, it is crucial to implement educational mechanisms that guarantee students' acquisition of these competences to fulfil the demanding needs of companies. In this case, traditional educational methods have become obsolete and new teaching methods are needed to instruct efficiently in technical and technological skills and prepare suitable professionals. Among the educational methodologies, project-based learning (PBL) is an approach that allows students to acquire key knowledge and skills through the elaboration of a project to solve a real problem. 
Based on the identification of the scarcity of professionals with in-depth technological knowledge and taking advantage of the PBL methodology, this paper presents a case study inspired by an industrial company that currently uses a production scheduling and control system, particularly, MESView for tracking its manufacturing activities. The PBL model presented in the case study involves two subjects: Information Systems and Supply and Demand Management. The main contribution of this communication is to illustrate the use of such a commercial MES in the University Master's Degree in Organisational and Logistics Engineering (MOLE), so that it can serve as a reference point for the elaboration of educational materials in the field of subjects related to information systems and production management.

\section{DESCRIPTION OF THE EDUCATIONAL CONTEXT}

\subsection{University Master's Degree in Organisational and Logistics Engineering (MOLE)}

As aforementioned, in the current economic context, companies need, more than ever, professionals capable of improving their production and logistics systems, eliminating inefficiencies and increasing productivity and competitiveness. Organisational and Logistics Engineering is an area that is distinguished from other master's degrees because it provides the future professionals with twofold skills: (i) the principles of engineering and also; (ii) the abilities for the organization and management of people and projects.

The objective of MOLE is to train professionals for the company who are capable of analyzing, modeling, designing, implementing and improving complex systems made up of people, materials, money, information, machines, technology and energy, in order to offer products and services in the shortest time and with the highest possible productivity, quality, reliability and efficiency.

Students will be trained in the design of production and logistics systems subject to technical and resource restrictions, the evaluation of the performance of such systems, detecting and prioritizing areas for improvement and the management of these systems in operation [3].

MOLE is framed within the knowledge domain of "Engineering and Architecture. Management" and it is taught, in Universitat Politècnica de València (UPV), at the Higher Polytechnic School of Alcoy. The Master's Degree is composed by 90 European Credit Transfer and Accumulation System (ECTS) divided into 2 courses ( 3 semesters) and structured in: (i) Mandatory subjects: 42 ECTS (Table 1); (ii) Elective Subjects: 36 ECTS (Table 2) and (iii) Master's Final Project: 12 ECTs.

Table 1. Module 1: Compulsory Subjects of MOLE.

\begin{tabular}{l|c|c|c|c|c}
\hline \multicolumn{1}{c|}{ Subject } & Course & Sem. & $T_{E C T S}$ & $P_{E C T S}$ & ECTS \\
\hline Estimation of Productive and Logistics Costs & 1 & $\mathrm{~A}$ & 3 & 3 & 6 \\
\hline Human resources management & 1 & $\mathrm{~A}$ & 3 & 3 & 6 \\
\hline Logistics & 1 & $\mathrm{~A}$ & 3 & 3 & 6 \\
\hline Quantitative Methods of Industrial Organization & 1 & $\mathrm{~A}$ & 3 & 3 & 6 \\
\hline Work Organization & 1 & $\mathrm{~B}$ & 3 & 3 & 6 \\
\hline Production Organization & 1 & $\mathrm{~B}$ & 3 & 3 & 6 \\
\hline Information systems & 1 & $\mathrm{~A}$ & 3 & 3 & 6 \\
\hline \hline
\end{tabular}

Sem.: Semester; $\boldsymbol{T}_{\text {ECTS }}$ : Theoretical ECTS; $\boldsymbol{P}_{\text {ECTS: }}$ Practical ECTS; ECTS: Total ECTS. 
Table 2. Module 2: Elective Subjects of MOLE.

\begin{tabular}{|c|c|c|c|c|c|c|}
\hline Area & Subject & Course & Sem. & $T_{E C T S}$ & $P_{E C T S}$ & ECTS \\
\hline \multirow{3}{*}{$\begin{array}{l}\text { Manufacturing } \\
\text { Processes }\end{array}$} & Manufacturing Process Automation & 1 & $\mathrm{~B}$ & 3 & 3 & 6 \\
\hline & Plant Design and Maintenance & 1 & $\mathrm{~B}$ & 3 & 3 & 6 \\
\hline & Advanced Manufacturing Technologies & 1 & $\mathrm{~B}$ & 3 & 3 & 6 \\
\hline \multirow{3}{*}{$\begin{array}{l}\text { Quality and } \\
\text { Prevention }\end{array}$} & Statistical Quality Control & 1 & $\mathrm{~B}$ & 3 & 3 & 6 \\
\hline & Prevention of occupational hazards & 1 & $\mathrm{~B}$ & 3 & 3 & 6 \\
\hline & Integrated Management Systems & 1 & $\mathrm{~B}$ & 3 & 3 & 6 \\
\hline \multirow{3}{*}{$\begin{array}{l}\text { Sustainability and } \\
\text { Environment }\end{array}$} & Environmental engineering & 1 & $\mathrm{~B}$ & 3 & 3 & 6 \\
\hline & Sustainable Processes and Technologies & 1 & $\mathrm{~B}$ & 3 & 3 & 6 \\
\hline & Eco-efficiency in the use of Materials & 1 & $\mathrm{~B}$ & 3 & 3 & 6 \\
\hline \multirow{4}{*}{$\begin{array}{l}\text { Procurement and } \\
\text { Distribution }\end{array}$} & Purchasing and Procurement & 2 & $\mathrm{~A}$ & 3 & 3 & 6 \\
\hline & Demand and Supply Management & 2 & A & 3 & 3 & 6 \\
\hline & Transport in Logistics & 2 & A & 3 & 3 & 6 \\
\hline & External Internships & 2 & $\mathrm{~A}$ & 6 & 0 & 6 \\
\hline \multirow{4}{*}{$\begin{array}{l}R+D+i \text { in } \\
\text { Product and } \\
\text { Process }\end{array}$} & Product and Process Design & 2 & A & 3 & 3 & 6 \\
\hline & Innovation Management & 2 & A & 3 & 3 & 6 \\
\hline & R\&D Project Management & 2 & A & 3 & 3 & 6 \\
\hline & $\begin{array}{l}\text { Research Methodologies in Organization } \\
\text { and Logistics Engineering }\end{array}$ & 2 & $A$ & 3 & 3 & 6 \\
\hline \multirow{3}{*}{$\begin{array}{l}\text { Strategic } \\
\text { Direction }\end{array}$} & Business Strategy & 2 & A & 3 & 3 & 6 \\
\hline & Marketing & 2 & A & 3 & 3 & 6 \\
\hline & $\begin{array}{l}\text { Economic Environment of the Industrial } \\
\text { Company }\end{array}$ & 2 & A & 3 & 3 & 6 \\
\hline
\end{tabular}

Finally, and in order to finish the MOLE, students have to develop a master's final project of 12 ECTs.

\subsection{Subjects Involved in the PBL Model}

The Information Systems subject is arranged according to the ECTS as part of the teaching program implemented at the Higher Polytechnic School of Alcoy, as indicated in Table 3. In the same way, Table 4 provides the information related to the ECTS of the Supply and Demand Management subject.

Table 3. ECTS Information Systems subject.

\begin{tabular}{|c|c|}
\hline ECTS Type & ECTS \\
\hline Theory & 2,50 \\
\hline Seminar & 0,50 \\
\hline Exercises & 1,50 \\
\hline Practical/Informatics & 1,50 \\
\hline Total & 6,00 \\
\hline
\end{tabular}

Table 4. ECTS Supply and Demand Management subject.

\begin{tabular}{|c|c|}
\hline ECTS Type & ECTS \\
\hline Theory & 2,50 \\
\hline Seminar & 0,50 \\
\hline Exercises & 1,30 \\
\hline Practical/Informatics & 1,30 \\
\hline Visits to enterprises & 0,40 \\
\hline Total & 6,00 \\
\hline
\end{tabular}

In the following sections both subjects will be described with regards to the: (i) teaching programme; (ii) teaching methods; (iii) recommended prior knowledge; and (iv) teaching scheduling.

\subsubsection{Information Systems}

The description of the first subject of the PBL model is shown as follows: 


\section{Teaching Programme}

- Didactic Unit I: Introduction to information systems

Estimated Duration: 4 hours.

Contents: Information systems roles in business environments, evolution of information systems infrastructure, network infrastructures, processing equipment, advanced network services

- Didactic Unit II: Information systems in supply chains and interoperability Estimated Duration: 2 hours.

Contents: System concept, information systems classification according to supported business functions, information systems classification according users' profiles, information systems interoperability in industrial firms: ISA-95 standard

- Didactic Unit III: Information systems as a support for Business Process Management Estimated Duration: 6 hours.

Contents: Business process, business process management, basic process terminology, life cycle of process management, business process management systems.

- Didactic Unit IV: Databases

Estimated Duration: 10 hours.

Contents: Introduction to databases, databases manager systems, databases conceptual modelling, logical and physical models, definition and manipulation languages.

- Didactic Unit V: Industry 4.0 and information systems trends

Estimated Duration: 7 hours.

Contents: Industry 4.0 and $4^{\text {th }}$ industrial revolution, digital transformation in firms, technological trends in a near future, cybersecurity

- Didactic Unit VI: Manufacturing execution systems (MES)

Estimated Duration: 10 hours.

Contents: Control applications (levels 0,1,2 in ISA-95), production management applications (level 3 in ISA-95).

- Didactic Unit VII: Enterprise resource planning systems (ERP)

Estimated Duration: 12 hours.

Contents: ERP systems characteristics, benefits and risks of ERP systems, evolution of ERP systems, architecture of ERP systems, Suppliers of ERP systems, life cycle of ERP systems, ERP alternatives assessment.

- Didactic Unit VIII: Business intelligence

Estimated Duration: 9 hours.

Contents: Business intelligence and decision support systems, datawarehouses, ETL, OLAP.

\section{+ Teaching Methods}

This subject uses different teaching methodologies such as: participative master classes, case studies, seminar discussion groups and simultaneous dialogue, teamworking and practical sessions.

\section{+ Recommended Prior Knowledge}

To make students take advantage of the full potential of the subject, prior about basic concepts of computer science and business management knowledge has been defined as recommended.

\section{+ Teaching Scheduling}

Table 5 shows the scheduling (in 15 weeks) indicating the number of hours devoted to each didactic unit according to ECTS type. 
Table 5. Information Systems subject Scheduling.

\begin{tabular}{c|c|c|c|c}
\cline { 3 - 5 } Weeks & Unit & $\begin{array}{c}\text { Theory + } \\
\text { Exercises }\end{array}$ & Seminars & $\begin{array}{c}\text { Practical/ } \\
\text { Informatics }\end{array}$ \\
\hline W1 & U1 & 4 & & \\
\hline W2 & U2-U3 & 4 & & \\
\hline W3 & U3 & 3 & 1 & \\
\hline W4 & U4 & 3 & & \\
\hline W5 & U4 & 2 & & 2 \\
\hline W6 & U4 & 2 & & 2 \\
\hline W7 & U5 & 3 & & \\
\hline W8 & U5 & 2 & 2 & 2 \\
\hline W9 & U6 & 4 & & 2 \\
\hline W10 & U6 & 2 & & 15 \\
\hline W11 & U7 & 2 & 1 & 2 \\
\hline W12 & U7 & 1 & 1 & \\
\hline W13 & U7 & 2 & & \\
\hline W14 & U8 & 3 & & \\
\hline W15 & U8 & 3 & & \\
\hline & Total & $\mathbf{4 0}$ & $\mathbf{5}$ & \\
\hline \hline
\end{tabular}

\subsubsection{Supply and Demand Management}

The description of the second subject of the PBL model is shown as follows:

\section{Teaching Programme}

- Didactic Unit I: Demand Forecast

Estimated Duration: 14 hours.

Contents: Types of Forecasts. Time Series Analysis. Causal Relationship Forecasts

- Didactic Unit II: Demand Management

Estimated Duration: 16 hours.

Contents: Demand Management Process. Demand Analysis. Product Segmentation

- Didactic Unit III: Order Fulfillment Strategies

Estimated Duration: 14 hours.

Contents: Make-to-Stock (MTS). Make-to-Order Production (MTO). Make-to-Order Assembly (ATO). Design to Order (ETO)

\section{- Didactic Unit IV: Replenishment Systems}

Estimated Duration: 16 hours.

Contents: Vendor Managed Inventory (VMI). Supplier Managed Inventory (SMI). Quick Response (QR). Continuous Replenishment Program (CRP). Efficient Consumer Response $(\mathrm{ECR})$

\section{Teaching Methods}

This subject uses different teaching methodologies such as: participative master classes, case studies, seminar discussion groups and simultaneous dialogue, teamworking and practical sessions.

\section{+ Recommended Prior Knowledge}

To make students take advantage of the full potential of the subject, the following prior knowledge has been defined as recommended: 
- Quantitative Methods for Industrial Organization: Particularly inventory aspects related to the replenishment systems such as economic order quantity (EOQ).

- Production Management: Specially planning aspects such as materials requirements planning related to the order fulfilment strategies.

- Information Systems: Specifically, using MES systems as a supporting tool to take decisions about the order fulfilment process and the analysis of orders performance considering replenishment systems.

\section{+ Teaching Scheduling}

Table 6 shows the scheduling (in 15 weeks) indicating the number of hours devoted to each didactic unit according to ECTS type.

Table 6. Supply and Demand Management subject Scheduling.

\begin{tabular}{c|c|c|c|c|c}
\cline { 3 - 6 } & \multicolumn{5}{c}{ Hours } \\
\hline Weeks & Unit & $\begin{array}{c}\text { Theory + } \\
\text { Exercises }\end{array}$ & Seminars & $\begin{array}{c}\text { Practical/ } \\
\text { Informatics }\end{array}$ & Visits \\
\hline W1 & U1 & 3 & & & \\
\hline W2 & U1 & 2 & 1 & 2 & \\
\hline W3 & U1 & 3 & & & \\
\hline W4 & U2 & 2 & 1 & 2 & \\
\hline W5 & U2 & 3 & & & \\
\hline W6 & U2 & 3 & & 2 & \\
\hline W7 & U3 & 2 & 1 & & \\
\hline W8 & U3 & 2 & 1 & 2 & \\
\hline W9 & U3 & 3 & & & \\
\hline W10 & U4 & 2 & 1 & 2 & \\
\hline W11 & U4 & 3 & & & \\
\hline W12 & U4 & 3 & & & \\
\hline W13 & U1,U2,U3,U4 & 3 & & & \\
\hline W14 & U1,U2,U3,U5 & - & & & \\
\hline W15 & Evaluation & 4 & & & \\
\hline & Total & $\mathbf{3 8}$ & $\mathbf{5}$ & & \\
\hline
\end{tabular}

\section{OVERVIEW OF THE PROJECT-BASED LEARNING (PBL) METHODOLOGY}

Currently, the professional needs demanded by companies are increasingly exigent. The higher education learning process should be adapted to these emerging needs. Project-Based Learning (PBL) is an active methodology in which the main actor is the student. This type of methodologies are not new, however there are few evidences of its use in Higher Education. Moreover, the COVID-19 outbreak is not helping academics in its use and implementation. Although it is worth mentioning that projects can be used as a learning approach in both presential and online teaching. For example, projects of software development imparted in Computers Engineering could be performed online through the PBL methodology.

The complex and unpredictable nature of projects generates serious challenges for students. Th PBL methodology is a comprehensive approach to classroom teaching and learning that is designed to engage students in investigation of authentic problems [4]. The benefits of the PBL methodology are highlighted by several authors [5-6]. Some of these benefits are described as follows: (i) Collaboration: It allows students to draw on each other's viewpoints and capacities in order to more effectively solve the project challenges; (ii) Problem Solving: Students in an autonomous-driven way learn how to solve real problems; (iii) Creativity: Students should be innovative and imaginative to find solutions to the difficulties of the project; (iv) In-depth understanding: Students learn by doing while they solve the project and this direct purposeful experience allows to retain and remember a higher 
percentage of what they do; (v) Critical thinking: Students ask questions and study analytical and judiciously all the potential solutions for their project; (vi) Resilience: When students are working to solve a project, they find difficulties and barriers [7] and they learn how dealt with and learn from failure; (vii) Motivation: students feel more confident in the resolution of the project challenges and in this sense, they are more likely to experience intrinsic or autonomous motivation; (viii) Coordination among subjects. PBL provides advantages of the synergies and complementarities among different subjects what allows a vertical and horizontal coordination by means of the project; and (iv) Encourage a continuity vision. PBL provides an integrated view of the different educational contents and not isolated portions of knowledge framed in each subject.

For all these reasons, PBL has been considered as an appropriate methodology for an adequate and consistent education in competences.

\section{CASE STUDY}

This application describes the collaborative project that has been defined in the subjects described in sections 2.1 and 2.2. with two-fold objectives: (i) to enhance the coordination between the contents of both subjects and (ii) to provide students with a continuous and integrated view that the project requires in both subjects.

\subsection{Motivation}

The motivation of incorporating PBL on these two subjects has its origin in the Institutional Educational Innovation and Improvement Project (PIME) that it is currently being developed at the Higher Polytechnic School of Alcoy (EPSA) of Universitat Politècnica de València (UPV). UPV considers of utmost importance to introduce PBL in the bachelors and masters' degrees to promote the learning of competencies (knowledge + skills + attitudes). Different studies have shown that active methods, as $\mathrm{PBL}$, are the most compatible and consistent with competences learning [8].

The main objective of this project PIME is to develop competences-based learning, through the implementation of methodologies that promote active student learning, by means the PBL methodology [9]. The bachelor degrees consist of 4 years and the PBL methodology is being implemented in the $3^{\text {rd }}$ and $4^{\text {th }}$ courses. This is due to the fact that during the first two years the learning process is focused on the conceptual and theoretical knowledge and the two last courses are focused on putting int practice what student have learnt previously to be adding to the existing knowledge new one through projects development. The activities defined to be performed in this PIME project are the following ones:

- Activity 1 . Identify the $3^{\text {rd }}$ and $4^{\text {th }}$ year subjects of each of the degrees imparted at EPSA to be integrated into the PBL model. It is worth mentioning that at EPSA 6 bachelors' degrees are imparted: (i) Business Administration and Management; (ii) Electrical Engineering; (iii) Industrial Design and Product Development Engineering; (iv) Computer Engineering; (v) Mechanical Engineering; and (vi) Chemical Engineering.

- Activity 2. Identify the training needs of the lecturers involved in the selected subjects of the previous activity.

- Activity 3. Design a training plan for lecturers with experts in the implementation of the PBL methodology in other degrees.

- Activity 4. Develop for each of the degrees the appropriate PBL model to be implement in the next year.

- Activity 5. Develop a monitoring plan to assess the impact on students' learning process with regards to the acquisition of competences and skills.

- Activity 6. Implement the PBL models developed in each degree and assess the results (students and lecturers' satisfaction, students' grades...) of the implementation of PBL models for the transfer of this methodology to other courses and degrees.

The duration of the PIME Project is 2 years. This course 2020-2021 the project is in the second year and the PBL models are being implemented. Figure 2 shows the schedule of the PRIME project that provides the foundations (arrows) for the development of the MOLE Project PBL model of this contribution. Readers are referred to some of the PBL models defined in the different degrees of the PIME Project such as Computer Engineering [10-11]; Mechanical Engineering [12-14]; Chemical 
Engineering [15]; among others. Moreover, the different phases of the MOLE Project are also depicted on Figure 2.

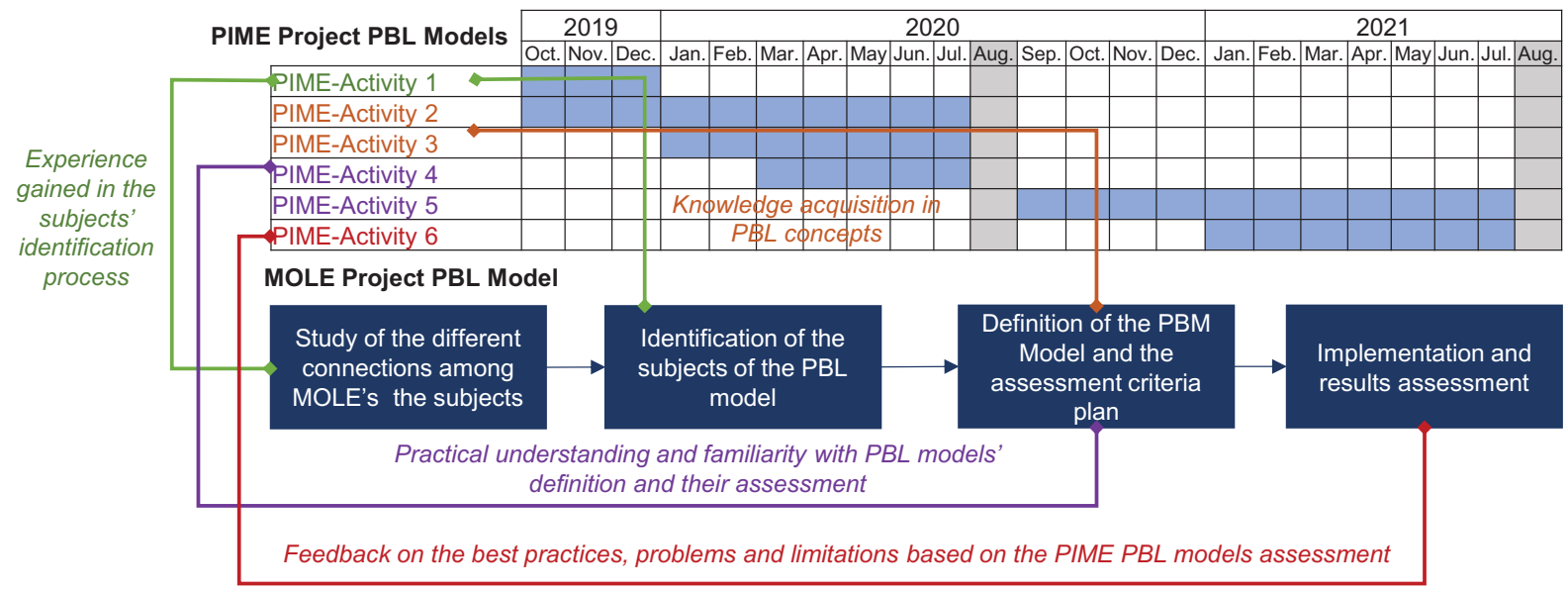

Figure 1. PIME Project schedule and foundations for the MOLE PBL model.

\subsection{Theoretical Basis: Manufacturing Execution System (MES)}

In the last decades, the investment in information systems by large, small and medium-sized companies, with the aim of increasing their productivity can be highlighted. This fact can be reflected in the growing development of the market for enterprise resource planning (ERP) systems in recent years. However, despite the widespread presence of this type of system, ERPs often do not pay attention to the production or workshop environment [16]. As a result, many companies decide to develop their own applications, acquire specific ones, or use spreadsheets or databases to support manufacturing operations such as real-time data acquisition and monitoring. These types of software applications used for production process control, quality assurance or personnel control, generally work independently without any integration with other information systems. However, in a real production environment, these tasks cannot be treated in isolation, due to their interdependence. In this context, it become necessary the emergence of information systems, MES systems, which could perform a common management and data acquisition from different areas of the manufacturing environment in order to ensure a reduction in production, response time, and costs and an enhancement of quality.

There are multiple definitions of MES systems. Among them, the Bridgefield Group [1] defines them as: "A production scheduling and tracking system used to analyze and report resource availability and status, schedule and update orders, collect detailed execution data such as material usage, labor usage, process parameters, order and equipment status, and other critical information."

In this sense, in order to fulfil the needs of the manufacturing environments, reference [17] identify 11 main functions associated with MES systems: 1. Resource allocation and status; 2. Detailed operations scheduling; 3. Dispatch/execution of production units; 4. Document Control; 5. Data acquisition/collection; 6. Labor Management; 7. Quality Management; 8. Process Management; 9. Maintenance Management; 10. Product Tracking and 12. Performance analysis

The publication of the S95 standard by Instrumentation, Systems \& Automation (ISA) Committee involves identifying the interactions between the different parts of the MES systems, as well as their relationship with the rest of the information systems of the company. According to the S95 standard, MES systems are located in a central area between the manufacturing level, where the manufacturing automation systems are, and the business level with planning systems such as ERP or supply chain planning systems. The S95 is widely used and provides business software providers with a terminology and a model of the flow of information among the different areas of the manufacturing environment and the different departments of the company [18]. The different functionalities of the MES systems allow companies to improve its global performance level and achieve a better adaptation to the customers' orders. In this sense, [19] identifies, in a quantitative way, the improvements in a representative industrial company when using an MES system: reduction of the cycle time $(45 \%)$, reduction of the input data processing time between independent systems $(75 \%)$, reduction of the loss of paper information $(57 \%)$, reduction of manufacturing time $(32 \%)$, among others. 


\subsection{PBL Model}

Among the main contents of the Information Systems subject, it can be highlighted the strategic application of information systems in companies and a comprehensive review of the essential applications in a business-industrial environment such as the ERP systems and the MES systems, among others. Likewise, these contents are consolidated by means the definition of project-based activities in a coordinated and collaborative way for encouraging the in-depth knowledge related to the MES systems. MES application is also considered as a supporting tool to take decisions about the order fulfilment process and the analysis of some aspects such as efficiency and productivity of orders management, taking into account replenishment systems. The practical experience presented has been designed to be carried out in groups, preferably of 2 students, with the complementary objective of encouraging discussion and critical analysis. As a prerequisite, students must be familiar with the basic operation of the MESview application. The main tasks to be carried out are 3:

1. Parameterization of an industrial case (in Information Systems sessions)

2. Introduction and monitoring of an order based on a Make-to-Order (MTO) fulfilment strategy (in Supply and Demand Management sessions)

3. Analysis of historical data from a production period (in Supply and Demand Management sessions)

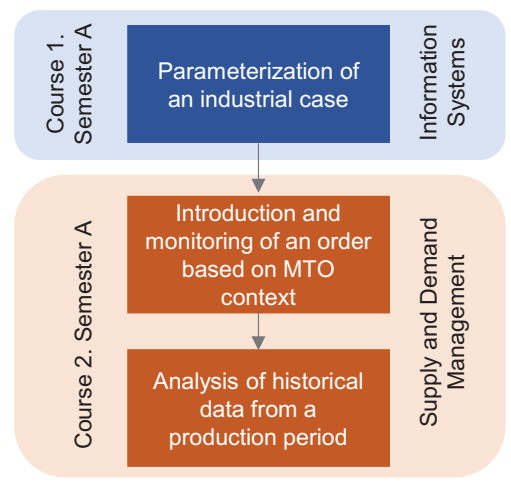

Figure 2. MOLE PBL model activities.

The parameterization task consists of studying a vegetable packaging company, with data modified for privacy reasons, and identifying the values corresponding to the parameters for establishing the structure of the industrial plant and its resources, as well as its operating characteristics in the MESView ${ }^{\circledR}[2]$ application for the desired working conditions. The laboratory sessions will only focus on the area called Multis and on resource number 2, which is a salad packing machine. Students receive general information about the operation of resource 2. It is a set of machines that work in coordination for the packaging of salads that are then frozen. These salads are packed in boxes of different sizes, but never more than $1 \mathrm{~kg}$. The resource is managed by 2 operators (permanent and temporary) with $100 \%$ dedication to this resource and a line manager who works at $50 \%$ dedication. The resource usually has a loss of about 3 minutes per hour in small unwanted stops, and also requires 6 minutes, every hour, to replenish the boxes of the packaging. Stoppages of more than 5 seconds are rare. In this resource we handle 4 different products that are: (1) EN10: Normal Salad 250 gr. (2) EN20: Normal salad of 500 gr. (3) EN10E Extra Salad 250 gr. and (4) EN20E Extra Salad $500 \mathrm{gr}$.

For the $250 \mathrm{gr}$. boxes the maximum speed of packaging is 1.600 boxes/hour, while for the $500 \mathrm{gr}$. boxes, it is 1.200 boxes/hour. For the EN10 and EN20 products it is desired to work in conditions of maximum performance, since it is considered that the products are not problematic. It is also desired to have information regarding slow production of high sensitivity. On the other hand, it is known that the average number of units/hour in this case is 1.450 units for EN10 and 1.050 units for EN20. For the extra products (EN10E and EN20E), it is recommended to work at most $80 \%$ of the maximum speed, since it is considered that products are more delicate. Slow production information should not be too sensitive. It is also known that the average number of units/hour is in this case 1.200 units for EN10E and 900 for EN20E.

Once the groups have discussed the various alternatives and defined the most appropriate combination, a pooling exercise is performed to find out the opinions of all the groups. This stage usually lasts approximately 45-60 minutes. From this point on, a more systematic stage of introducing the values into the application is carried out, which usually takes about 30 minutes, and a final verification stage is also performed in approximately 15 minutes. This first session ends with a summary of the milestones achieved and the meaning of the practice in the context of the Information Systems subject. 
In the second session, planned to be held in the Demand and Supply Management subject, students review the work performed in the first activity and mature the knowledge acquired linked to how a MES system is configured. During this second session, the functionality and purpose of this type of system will be addressed and tasks 2 and 3 will be performed. For task 2, introduction and follow up of an order in MTO environments, a signal server is set up for resource 2. In this way, the existence of the real resource is simulated, so that the person in charge of the practical session can keep it running or stop it temporarily by simulating breakdowns, technical stops, etc. In turn, each group must include a new manual production order on resource 2 for some number of units of one of the possible products (EN10, EN200, EN10E or EN20E) in the monitoring menu. Once the order has been entered, the group of students can follow it up in the summary report. This data is the same as can be seen in the following task. The difference is that, in this case, the information varies in real time, depending on the speed and regularity of the simulated signal. This allows users to appreciate changes in status and link the evolution of the signal received to changes in information. This task has proved to be very effective for users to understand the usefulness of the application. In task 3 , the analysis of historical data from a production period is performed. With this task, students seek to understand the concepts of productions speed, production efficiency and states. To do this, an order number is provided whose data are known and whose calculations can be easily reproduced.

And finally, in this area of analysis, students are invited to carry out a study of the set of states through which an order has passed and how the times assigned to each state contribute to the efficiency and productivity previously analyzed. With these three tasks students should reach a global idea about the use of MES tools, starting with the design (in Information Systems subject) and ending with the data analysis (in Supply and Demand Management subject).

\section{CONCLUSIONS}

This work presents the definition of a PBL model related to the use of a MES system and involving two subjects: Information Systems and Supply and Demand Management of the MOLE degree. The MOLE Degree has been globally presented, contextualizing the subjects previously mentioned by focusing on skills, and on coordinating and organizing the subject and teaching-learning methodologies whose thematic units are also detailed. The main characteristics of the active PBL methodology have been described, highlighting its benefits. The motivation for the definition of the PBL model of this work is based on the results that are currently being obtained in an institutional educational innovation and improvement project (PIME). The outputs of this PIME project are the inputs, in the form of good practices, recommendations, etc. for the design of the PBL model of the previous two subjects at the master's level. The PBL model defined model is based on the use of MES systems and therefore, this work describes the main characteristics of these MES systems. Finally, it is detailed how the different sessions have been scheduled and the application of the MESView on a real example. Through this real example and the proposed exercises, students can learn about the process of parametrization of the system, the introduction and monitoring of an order based on a MTO context and the analysis of historical data from a production period.

\section{ACKNOWLEDGEMENTS}

This article has been supported by Universitat Politècnica de València, particularly by the Vicerectorate for Digital Resources and Documentation (Vicerrectorado de Recursos Digitales y Documentación) and Vice-Rectorate for Studies, Quality and Accreditation (Vicerrectorado de Estudios, Calidad y Acreditación) under the Call for Learning + Teaching (Convocatoria A+D2019: Aprendizaje + Docencia. Proyectos de Innovación y Mejora Educativa) and Project Code: A157. The authors would like to acknowledge the support of the Institute of Educational Sciences (Instituto de Ciencias de la Educación), the Evaluation and Monitoring Commission for Educational Innovation and Improvement Projects (Comisión de Evaluación y Seguimiento de Proyectos de Innovación y Mejora Educativa (CESPIME) and Escuela Politécnica Superior de Alcoy.

\section{REFERENCES}

[1] Bridgefield, "Bridgefield Group Supply Chain Glossary”, 2020. Retrieved from http://www.erpglossary.com/

[2] MESView, 2020. Retrieved from http://www.mesview.com/ 
[3] UPV-MUIOL, "Master's Degree in Organisational and Logistics Engineering", 2020. Retrieved from http://www.upv.es/titulaciones/MUIOL/indexi.html

[4] P.C. Blumenfeld, E. Soloway, R.W. Marx, J.S. Krajcik, M. Guzdial, A. Palincsar, "Motivating project-based learning: Sustaining the doing, supporting the learning", Educational psychologist, vol. 26, no. 3-4, pp. 369-398, 1991.

[5] P.A. Ertmer, K.D. Glazewski, "Essentials for PBL implementation: Fostering collaboration, transforming roles, and scaffolding learning" Essential readings in problem-based learning, pp. 89106, 2015.

[6] E. Dale. Audio-visual methods in teaching. New York: The Dryden Press, 1946.

[7] R. Sanchis, L. Canetta, R. Poler, "A Conceptual Reference Framework for Enterprise Resilience Enhancement", Sustainability, vol. 12, no. 4, 1464, 2020.

[8] F. Lasnier, F. Réussir la formation par compétences. Montréal: Guérin, 2000.

[9] R. Sanchis, J. Mula, B. Cantó Colomina, D. Garcia-Sanoguera, J.I. Torregrosa López, "Diseño de la Incorporación del Aprendizaje Basado en Proyectos en las Titulaciones de Grado del Campus de Alcoy de la Universitat Politècnica de València", VI Congreso Nacional de Innovación Educativa y Docencia en Red, Editorial Universitat Politècnica de València, 2020.

[10] J. Linares-Pellicer, J. Orta-López, J. Salavert-Torres, M.J. Segura Flor, J.A. Silvestre Cerdà, R. Sanchis, "Towards Inter-Subject Project-Based Learning in Programming-Related Courses at Computer Science Studies", EDULEARN Proceedings, pp. 3973 - 3978, 2020.1

[11] J. Esparza Peidro, E.J. Golf Laville, J.J Izquierdo-Doménech, J.V. Tomas Miquel, R. Sanchis, "Definition of Project-Based Learning Models in the Computer Engineering Degree", EDULEARN Proceedings, pp. 3966 - 3972, 2020.

[12] M. Pérez-Sánchez, M. Díaz-Madroñero Boluda, J. Mula, R. Sanchis, "The Sustainable Development Goals (SDGs) Applied to Higher Education. A Project Based Learning Proposal Integrated with the SDGs in Bachelor Degrees at the Campus Alcoy (UPV)", EDULEARN Proceedings, pp. $3997-4005,2020$.

[13] R. Balart, N. Montanes, L. Quiles-Carrillo, S. Jordá-Gisbert, H.C. Sanchis-Gomis, Sanchis, R., "Model Design and Calculation with Polymeric and Composite Materials through Project-Based Learning", EDULEARN Proceedings, pp. 3979 - 3986, 2020.

[14] M. Pérez-Sánchez, R. Sanchis, "Sustainable Development Goals Integrated in Project-Based Learning in the Mechanical Engineering Degree", INTED Proceedings, 2021.

[15] C. Carbonell, S.C. Cardona, I. Domínguez, V. Fombuena, M.F. López-Pérez, J. Lora, R. Sanchis, " Project-based learning as a coordination methodology between subjects in a Chemical Engineering degree", INTED Proceedings, 2021.

[16] L. Holst, "Integrating discrete-event simulation into the manufacturing system development process. Lund University, Department of Mechanical Engineering, Division of Robotic, 2001.

[17] MESA International, "MES explained: a high level vision. MESA International White Paper", 1997.

[18] B. Saenz de Ugarte, A. Artiba, R. Pellerin, R, "Manufacturing execution system - a literature review", Production Planning \& Control, vol. 20, no. 6, pp. 525-539, 2009.

[19] MESA International, "MESA White Paper \#02: MES Functionalities and MRP to MES Data Flow Possibilities", 1997. 